\title{
Genetic diversity in wild sweet cherries (Prunus avium) in Turkey revealed by SSR markers
}

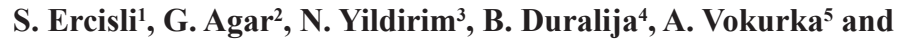 \\ H. Karlidag 6
}

${ }^{1}$ Department of Horticulture, Faculty of Agriculture, Ataturk University, Erzurum, Turkey

${ }^{2}$ Department of Biology, Faculty of Science, Ataturk University, Erzurum, Turkey

${ }^{3}$ Department of Biology, Faculty of Arts and Sciences, Erzincan University, Erzincan, Turkey

${ }^{4}$ Department of Pomology, Faculty of Agriculture, Zagreb University, Zagreb, Croatia

${ }^{5}$ Department of Plant Breeding, Genetics and Biometrics, Faculty of Agriculture, Zagreb University, Zagreb, Croatia

${ }^{6}$ Department of Horticulture, Faculty of Agriculture, Inonu University, Malatya, Turkey

Corresponding author: S. Ercisli

E-mail: sercisli@gmail.com

Genet. Mol. Res. 10 (2): 1211-1219 (2011)

Received December 6, 2010

Accepted March 24, 2011

Published June 21, 2011

DOI 10.4238/vol10-2gmr1196

ABSTRACT. Wild sweet cherry (Prunus avium) trees are abundant in the northern part of Turkey, including the Coruh Valley. We analyzed 18 wild sweet cherry genotypes collected from diverse environments in the upper Coruh Valley in Turkey to determine genetic variation, using 10 SSR primers. These SSR primers generated 46 alleles; the number of alleles per primer ranged from 3 to 7 , with a mean of 4.6. The primer PS12A02 gave the highest number of polymorphic bands $(\mathrm{N}=7)$, while CPSCT010, UDAp-401 and UDAp-404 gave the lowest number 
$(\mathrm{N}=3)$. Seven groups were separated in the dendrogram, although most of the genotypes did not cluster according to phenological and morphological traits. This level of genetic diversity in these wild sweet cherry genotypes is very high and therefore these trees would be useful as breeders for crosses between cultivated sweet cherry and wild genotypes.

Key words: Genetic diversity; SSR markers; Microsatellites; Wild sweet cherry

\section{INTRODUCTION}

Turkey encompasses a high level of plant diversity and is recognized as a center of diversity for globally significant temperate zone fruit crops, like hazelnuts, sweet and sour cherries, apples, chestnuts, walnuts, apricots, pears, quinces, and almonds. Turkey is also described as a country with many microcenters for other crops, such as wheat, flax, barley, melon, cabbage, and bean. The importance of protecting existing plant diversity is highly recognized and various conservation programs exist in the country (Ercisli, 2004; Halilova and Ercisli, 2010).

Located in the northeastern part of the country, the Coruh Valley shows high plant biodiversity in its relatively small area. The valley is classified as one of the 34 hotspots by the World Conservation Union, as the western section of the "Caucasus Ecosystem" (Anonymous, 2009). Its rich biological diversity, in particular for wild edible fruits including wild cherries, is a result of the extreme variations in climate within a very small area and varying altitudes of the valleys where the difference between the lowest and the highest point can reach up to 3000 meters.

Sweet cherry (Prunus avium L.) is an important tree crop, which grows both wild and cultivated in many places in Turkey. It is mostly cultivated in temperate regions in the world and is thought to have originated around the Caspian Sea and the Black Sea and now is widely cultivated across Europe and western Asian countries (Webster, 1996). It is believed that the spread of its cultivation through Europe was probably based on domestication of wild individuals that are adaptable to different areas in Europe (Wünsch and Hormaza, 2002).

Currently in Turkey, wild sweet cherries are found in mixed forests (up to $1600 \mathrm{~m}$ a.s.1.), mainly in the northeastern part of the country. In particular the Coruh Valley in Northeast Anatolia has notable populations of different wild sweet cherry genotypes that differ from each other in tree vigor and habit, branching habit, fruit skin color and fruit taste, flowering and harvest time (Ercisli, 2004; Turkoglu et al., 2010). Seeds of wild sweet cherries are used as rootstocks for scion cultivars (Turkoglu et al., 2010). The fruit is an important food source in human nutrition, but it has also a significant place in the nutrition chain within the forest ecosystem as food for birds, mammals and insects. Local people in Northeast Anatolia region have traditionally used wild sweet cherry fruits, both as a source of food and as a medicine for hundreds of years. In Turkey, the fruit stalks of wild sweet cherries boiled in water are used as a diuretic and for urinary bladder problems (Baytop, 1984).

The majority of these wild sweet cherry genotypes are potentially useful genetic sources of resistance against diseases and pests, and available for cultivated sweet cherry improvement. Therefore, knowledge of the genetic variation of wild sweet cherry could be 
important for their efficient use in further breeding programs and for conservation purposes.

Molecular marker analysis, combined with phenotypic evaluation, is a powerful tool for grouping of genotypes based on genetic similarity data, and for selection of progenitors that might constitute new breeding populations. This tool is also very useful for identification and management of germplasm collections (Benjak et al., 2005; Kafkas et al., 2008).

Among the molecular markers, the microsatellites (or SSR - simple sequence repeats) are polymerase chain reaction (PCR)-based, highly polymorphic, multi-allelic, frequently codominant, highly reproducible and randomly and widely distributed in the genome (Powell et al., 1996). In sweet cherries, microsatellites have been used for germplasm characterization (Lacis et al., 2009), determination of genetic diversity (Dirlewanger et al., 2002; Wünsch et al., 2004), germplasm management (Wünsch and Hormaza, 2002), parentage analysis (Schueler et al., 2003), cultivar identification (Xuan et al., 2009; Gulen et al., 2010), and mapping genetic linkage (Olmstead et al., 2008). In Prunus, microsatellites developed in one species have been used in different species, demonstrating their transferability and ability to detect polymorphism (Wünsch, 2009).

In cultivated sweet cherries, many reports related to SSR analysis have been published (Wunsch and Hormaza, 2004; Lacis et al., 2009; Cheng and Huang, 2009; Turkoglu et al., 2010). However, much less has been done to assess genetic diversity of wild sweet cherries by molecular markers. A significant report comparing wild sweet cherry populations from Italy, Croatia and Slovenia by SSR markers was published by Guarino et al. (2009).

In the present study, 10 SSRs developed for Prunus were used to assess genetic diversity and genetic relationships among wild sweet cherry genotypes, focusing on understanding the variability among wild sweet cherries.

\section{MATERIAL AND METHODS}

\section{Plant material}

The 18 wild sweet cherry genotypes ( $P$. avium) were collected in diverse environments in the upper Coruh Valley and their DNA in leaves were used for microsatellite analysis. Some important tree and fruit characteristics of 18 genotypes are given in Table 1.

\section{DNA extraction}

Total genomic DNA was extracted from young leaf from a single tree for each genotype using the CTAB method (Doyle and Doyle, 1987). DNA purity and concentration were checked, both on $1 \%(\mathrm{w} / \mathrm{v})$ agarose gels by using 1.0X TBA buffer and with a NanoDrop ${ }^{\circledR}$ ND-1000 Spectrophotometer.

\section{SSR and PCR procedure}

From the initial screening of 27 SSR primers on agarose gel, a total 10 SSR primers were selected and used in SSR analysis for determining the genetic diversity of 18 genotypes of wild $P$. avium (Table 2). PCR was carried out in a volume of $25 \mu \mathrm{L}$ including $50 \mathrm{ng}$ template DNA, 1X PCR buffer, $1.5 \mathrm{mM} \mathrm{MgCl}, 0.2 \mathrm{mM}$ of each dNTP, 1.67 pmol of each SSR primer (forward and reverse), and 1.5 U Taq DNA polymerase (Sigma, USA). 
S. Ercisli et al.

1214

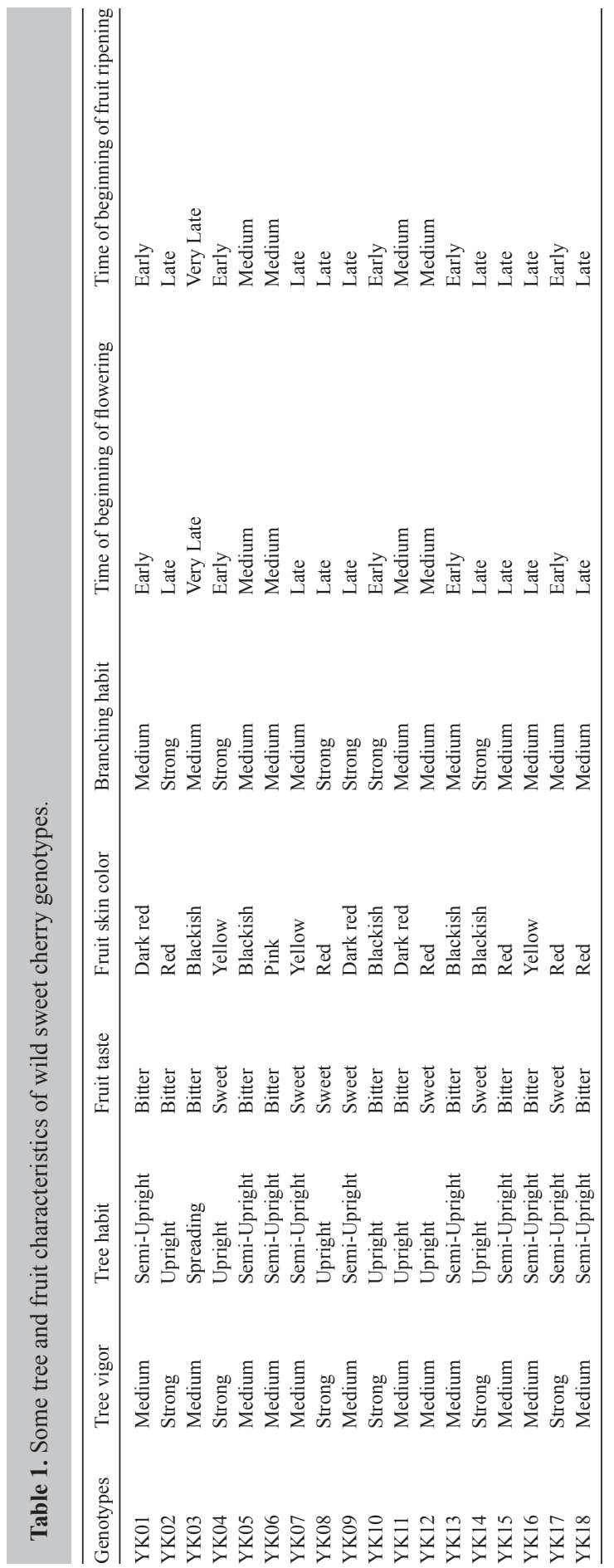


Table 2. List of microsatellites that produced polymorphic amplification patterns among the genotypes studied.

\begin{tabular}{|c|c|c|c|c|}
\hline Locus name & Repeat motif & Specie & Reference & No. of alleles \\
\hline CPSCT010 & $(\mathrm{TA})_{9}(\mathrm{CT})_{14}$ & Plum & Mnejja et al., 2005 & 3 \\
\hline UDAp-401 & $(\mathrm{TC})_{23}$ & Apricot & Messina et al., 2004 & 3 \\
\hline UDAp-404 & $(\mathrm{GA})_{21}$ & Apricot & Messina et al., 2004 & 3 \\
\hline Pchgms1 & $(\mathrm{AC})_{12}(\mathrm{AT})_{6}$ & Peach & Sosinski et al., 2000 & 6 \\
\hline UDP96001 & $\mathrm{CA}$ & Peach & Cipriani et al., 1999 & 6 \\
\hline UDP96005 & $\mathrm{AC} \& \mathrm{CT}$ & Peach & Cipriani et al., 1999 & 5 \\
\hline PS12A02 & $(\mathrm{GA})_{22}$ & Sweet cherry & Sosinski et al., 2000 & 7 \\
\hline UCDCH17 & $(\mathrm{CT})_{11}$ & Sweet cherry & Struss et al., 2003 & 4 \\
\hline $\mathrm{UCDCH} 21$ & $(\mathrm{CA})_{18}$ & Sweet cherry & Struss et al., 2003 & 5 \\
\hline UCDCH31 & $(\mathrm{CT})_{26}$ & Sweet cherry & Struss et al., 2003 & 4 \\
\hline Total & & & & 46 \\
\hline Average & & & & 4.6 \\
\hline
\end{tabular}

PCR amplification program was applied as follows: pre-denaturation at $94^{\circ} \mathrm{C}$ for 3 min; denaturation at $94^{\circ} \mathrm{C}$ for $30 \mathrm{~s}$, annealing at $45^{\circ} \mathrm{C}$ for $30 \mathrm{~s}$, extension at $72^{\circ} \mathrm{C}$ for $30 \mathrm{~s}, 30$ cycles, and a final extension at $72^{\circ} \mathrm{C}$ for $5 \mathrm{~min}$. PCR products were separated by electrophoresis on $3 \%$ high-resolution agarose gel in $1 \mathrm{X}$ TBE buffer at 180 constant volts for $1 \mathrm{~h}$, and visualized by staining with ethidium-bromide and photographed using the gel documentation system 'Bio-Rad Gel Doc 1000' under UV source.

Each polymorphic band was identified and scored as being present (1) or absent (0) on the gels for SSR analyses. A similarity matrix was generated according to simple matching coefficients (Sneath and Sokal, 1973). The data in the similarity matrix were used for cluster analysis using the unweighted pair-group method with arithmetic averages (UPGMA) by using the NTSYS-PC 2.2 software (Numerical Taxonomy and Multiware Analysis System, version 2.0) (Rohlf, 1998).

\section{RESULTS}

All 10 loci assayed in wild sweet cherry genotypes possessed a moderate level of polymorphism, with the number of alleles per locus ranging from 3 (CPSCT010, UDAp-401 and UDAp-404) to 7 (PS12A02). The PS12A02 locus was the most polymorphic among the 10 loci, with the highest effective number of alleles and was followed by Pchgms 1 and UDP96001 (6 alleles) (Table 2).

The genetic similarity measured within wild sweet cherry genotypes ranged from 0.33 to 0.90 with an average of 0.58 . The highest genetic similarity ratio was observed between YK15 and YK17 genotypes (0.90) while the lowest genetic similarity was observed between YK03 and YK18 genotypes (0.33), respectively.

A dendrogram constructed according to SSR data (Figure 1) of 18 wild sweet cherry genotypes divided them into 7 main clusters. The first cluster included YK11, the second cluster included YK18 and the third cluster included YK01 and YK06 genotypes with a 0.40 similarity ratio. The fourth cluster included YK09 and YK14 genotypes, which have a 0.49 similarity ratio (Figure 1). The fifth cluster, which has the majority of genotypes (9 genotypes), was also divided into two subclusters: the first subcluster consisted of YK02, YK05, YK13, YK15, and YK17. These genotypes are found to be genetically very close to each 
other. For example, the similarity ratio between YK15 and YK17 is 0.90 , and 0.82 for YK02 and YK05 (Figure 1). The second subcluster consisted of genotypes YK07, YK08, YK10, and YK16. Cluster six consisted of YK04 and YK12, and finally the last main cluster consisted only of genotype YK03 (Figure 1).

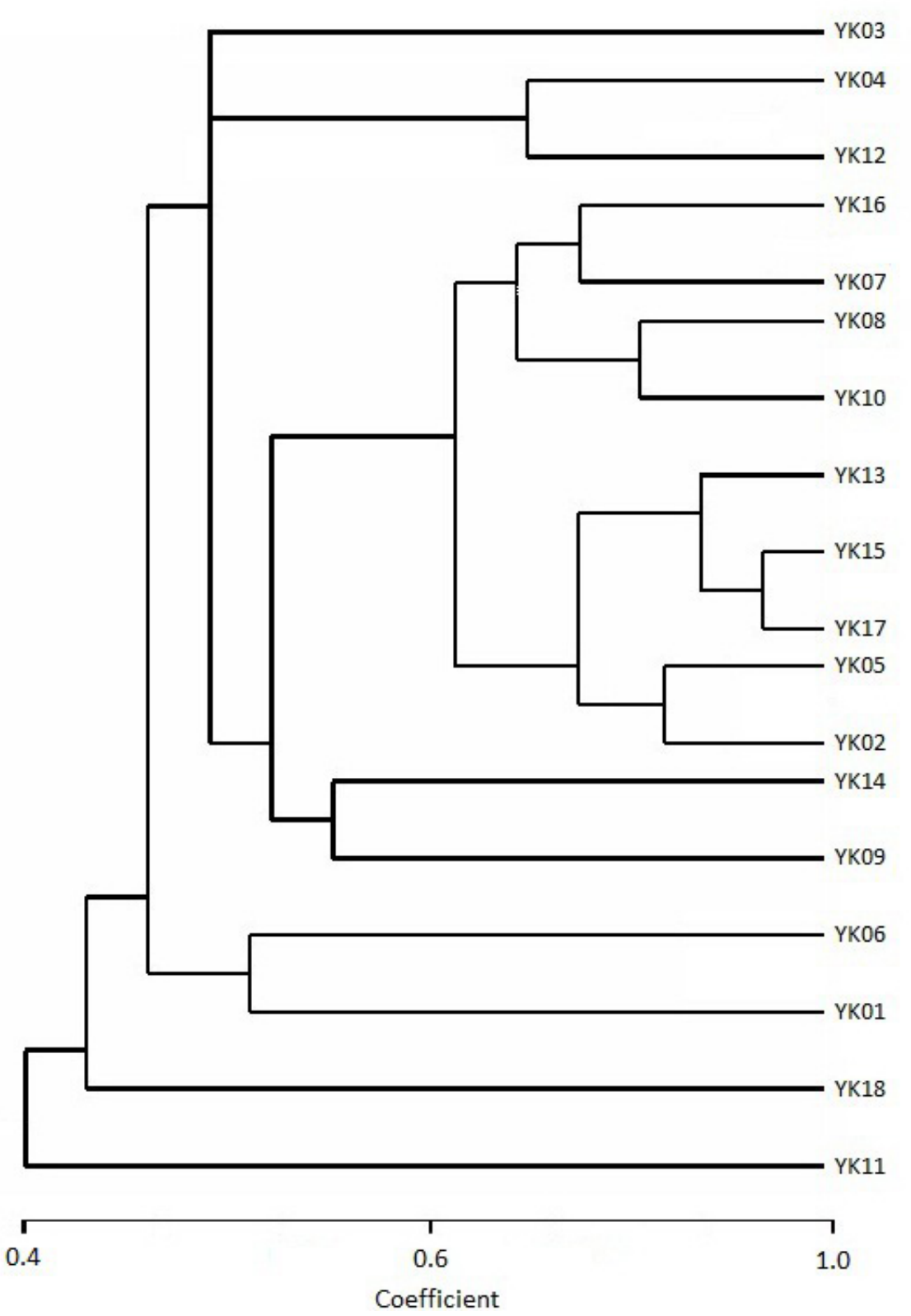

Figure 1. Dendrogram of 18 wild sweet cherry genotypes based on simple matching coefficient and UPGMA analysis of 46 SSR markers. 
In the present study, in most cases, wild sweet cherry genotypes within the same cluster did not have similar phenological and morphological characteristics. The majority of genotypes ( 9 genotypes) placed in cluster five (Figure 1) were found to have a high similarity ratio. However, most of the phenological and morphological characteristics of these 9 genotypes are differed (Table 1). For example, in cluster five, the closest genotypes (with a similarity ratio of $0.90)$, YK15 and YK17, presented differences in some tree and fruit characteristics. YK15 has medium tree vigor, bitter fruit taste and dark red fruit color. However, YK17 has strong tree vigor, sweet fruit taste and red fruit color (Table 1). The other closest genotypes, YK02 and YK05, with a similarity ratio of 0.82 , also have differences in some characteristics. YK02 has strong tree vigor, upright tree habit, red fruit color, strong branching habit, and late flowering and ripening time, while YK05 has medium tree vigor, semi-upright tree habit, blackish fruit color, medium branching habit, and late flowering and ripening characteristics (Table 1).

The other closest genotypes, for example, YK01 and YK06 and YK09 and YK14, also have many different phonological and morphological characteristics (Table 1).

\section{DISCUSSION}

Turkey is accepted as an origin and diversity center for sweet cherries. This study is the first report on genetic diversity among a number of wild grown sweet cherries sampled from the Coruh Valley in Turkey.

The primary results show that microsatellites can be effectively used for determining genetic diversity in wild sweet cherries. We obtained high quality, readable and variable levels of amplifications with all microsatellite primer pairs tested. We did not observe any two genotypes that shared identical SSR markers.

In the present study, 10 loci in wild sweet cherry genotypes were assayed. The number of alleles per locus ranged from 3 to 7 with an average of 4.6 putative alleles per locus. Previously, Kacar et al. (2005) obtained a total of 37 alleles among 10 sweet cherry cultivars by 9 SSR primers. Clarke and Tobutt (2003) used 14 sweet cherry cultivars for SSR analysis and determined 2 to 7 alleles per SSR primer. In addition Vaughan and Russell (2004) used 16 wild cherry accessions for molecular analysis by using 10 SSR primers and they obtained 2 to 6 alleles.

The PS12A02 locus developed for sweet cherry was the most polymorphic among the 10 loci, and produced the highest effective number of alleles ( 7 alleles) and was followed by Pchgms1 and UDP96001 (6 alleles). The results also confirm the high transferability of the SSR markers among different Prunus species. This transferability across Prunus species has already been confirmed by other authors (Dirlewanger et al., 2002; Wünsch and Hormaza, 2002; Bouhadida et al., 2009). Previously, the PS12A02 locus was found to be the most informative in several studies (Downey and Iezzoni, 2000; Wünsch and Hormaza, 2004; Turkoglu et al., 2010). The second most informative locus, Pchgms1, was also found to be very informative in sweet cherries (Wünsch et al., 2004; Gulen et al., 2010). Previously, SSR markers have been widely used for molecular characterizations and similarity relationships among sweet cherries and have revealed high polymorphism levels that discriminate the accessions (Dirlewanger et al., 2002; Wünsch and Hormaza, 2002; Wünsch et al., 2004; Kacar et al., 2005; Gulen et al., 2010). The relatively high level of intra-group variation observed within $P$. avium genotypes suggests complexities in the development of $P$. avium along the Black Sea 
and Northeast Anatolia in Turkey. The continuous seed propagation by birds, natural hybridization between indigenous and introduced plants, and human selection may have contributed to this variation. These heterozygosity are commonly observed among clonally propagated, outbreed, perennial species, since they are favored during selection and are known to confer greater adaptability, vigor and productivity in clonal varieties (Aradhya et al., 1998; Sefc et al., 2000).

In summary, the gene pool of wild sweet cherry in Northeast Anatolia in Turkey has an enough amount of genetic variation. Regarding germplasm management, our results show that the germplasm collection is variable and may be important for future Prunus avium breeding programs.

\section{REFERENCES}

Anonymous (2009). The World Conservation Union. Available at [www.iucn.org]. Accessed March 15, 2011.

Aradhya MK, Liana Y, Zee FT and Manshardt RM (1998). Genetic variability in Macadamia. Genet. Res. Crop Evol. 45: 19-32.

Baytop T (1984). Therapy with Medicinal Plants in Turkey. Istanbul University Publication, Turkey.

Benjak A, Ercisli S, Vokurka A, Maletic E, et al. (2005). Genetic relationships among grapevine cultivars native to Croatia, Greece and Turkey. Vitis 44: 73-77.

Bouhadida M, Casas AM, Gonzalo MJ, Arus P, et al. (2009). Molecular characterization and genetic diversity of Prunus rootstocks. Sci. Hortic. 120: 237-245.

Cheng Z and Huang H (2009). SSR fingerprinting Chinese peach cultivars and landraces (Prunus persica) and analysis of their genetic relationships. Sci. Hortic. 120: 188-193.

Cipriani G, Lot G, Huang WG, Marrazzo MT, et al. (1999). AC/GT and AG/CT microsatellite repeats in peach (Prunus persica (L) Batsch): isolation, characterisation and cross-species amplification in Prunus. Theor. Appl. Genet. 99: 65-72.

Clarke JB and Tobutt KR (2003). Development and characterization of polymorphic microsatellites from Prunus avium 'Napoleon'. Mol. Ecol. Notes 3: 578-580.

Dirlewanger E, Cosson P, Tavaud M, Aranzana MJ, et al. (2002). Development of microsatellite markers in peach [Prunus persica (L.) Batsch] and their use in genetic diversity analysis in peach and sweet cherry, Prunus avium L.). Theor. Appl. Genet. 105: 127-138.

Downey SL and Iezzoni AF (2000). Polymorphic DNA markers in black cherry (Prunus serotina) are identified using sequences from sweet cherry, peach and sour cherry. J. Am. Soc. Hortic. Sci. 125: 76-80.

Doyle JJ and Doyle JL (1987). A rapid DNA isolation procedure for small quantities of fresh leaf tissue. Phytochem. Bull. 19: 11-15.

Ercisli S (2004). A short review of the fruit germplasm resources of Turkey. Genet. Res. Crop Evol. 51: 419-435.

Guarino C, Santoro S, De SL and Cipriani G (2009). Prunus avium: nuclear DNA study in wild populations and sweet cherry cultivars. Genome 52: 320-337.

Gulen H, Ipek A, Ergin S, Akcay ME, et al. (2010). Assessment of genetic relationships among 29 introduced and 49 local sweet cherry accessions in Turkey using AFLP and SSR markers. J. Hortic. Sci. Biotechnol. 85: 427-431.

Halilova H and Ercisli S (2010). Several physico-chemical characteristics of cherry laurel (Laurocerasus officinalis Roem) fruits. Biotechnol. Biotechnol. Equip. 24: 1970-1973.

Kacar AY, Iezzoni A and Cetiner S (2005). Sweet cherry cultivar identification by using SSR markers. J. Biol. Sci. 5: 616-619.

Kafkas S, Ozgen M, Dogan Y, Ozcan B, et al. (2008). Molecular characterization of mulberry accessions in Turkey by AFLP markers. J. Am. Soc. Hortic. Sci. 133: 593-597.

Lacis G, Rashal I, Ruisa S, Trajkovski V, et al. (2009). Assessment of genetic diversity of Latvian and Swedish sweet cherry (Prunus avium L.) genetic resources collections by using SSR (microsatellite) markers. Sci. Hortic. 121: 451-457.

Messina R, Lain O, Marrazzo MT, Cipriani G, et al. (2004). New set of microsatellite loci isolated in apricot. Mol. Ecol. Notes 4: 432-434.

Mnejja M, Garcia-Mas J, Howad W and Arús P (2005). Development and transportability across Prunus species of 42 polymorphic almond microsatellites. Mol. Ecol. Notes 5: 531-535. 
Olmstead JW, Sebolt AM, Cabrera A, Sooriyapathirana SS, et al. (2008). Construction of an intra-specific sweet cherry (Prunus avium L.) genetic linkage map and synteny analysis with the Prunus reference map. Tree Genet. Genom. 4: 897-910.

Powell W, Morgante M, Andre C, Hanafey M, et al. (1996). The comparison of RFLP, RAPD, AFLP and SSR (microsatellite) markers for germplasm analysis. Mol. Breed. 2: 225-238.

Rohlf FJ (1998). NTSYS-PC Numerical Taxonomy and Multivariate Analysis System. Exeter Software, Setauket, New York.

Schueler S, Tusch A, Schuster M and Ziegenhagen B (2003). Characterization of microsatellites in wild and sweet cherry (Prunus avium L.) - markers for individual identification and reproductive processes. Genome 46: 95-102.

Sefc KM, Lopez MS, Lefort F, Botta R, et al. (2000). Microsatellites variability in grapevine cultivars from different European regions and evaluation of assignment testing to assess the geographic origin of cultivars. Theor. Appl. Genet. 100: 498-505.

Sneath PH and Sokal RR (1973). Numerical Taxonomy. Freeman, San Francisco.

Sosinski B, Gannavarapu M, Hager LD, Beck LE, et al. (2000). Characterisation of microsatellite markers in peach (Prunus persica (L.) Batsch). Theor. Appl. Genet. 101: 421-428.

Struss D, Ahmad R, Southwick SM and Boritzki M (2003). Analysis of sweet cherry (Prunus avium L.) cultivars using SSR and AFLP markers. J. Am. Soc. Hortic. Sci. 128: 904-909.

Turkoglu Z, Bilgener S, Ercisli S, Bakir M, et al. (2010). Simple sequence repeat-based assessment of genetic relationships among Prunus rootstocks. Genet. Mol. Res. 9: 2156-2165.

Vaughan SP and Russell K (2004). Characterization of novel microsatellites and development of multiplex PCR for largescale population studies in wild cherry; Prunus avium. Mol. Ecol. Notes 4: 429-431.

Webster AD (1996). The Taxonomic Classification of Sweet and Sour Cherries and a Brief History of Their Cultivation. In: Cherries: Crop Physiology, Production and Uses (Webster AD and Looney NE, eds). CAB International, Wallingford, 3-24.

Wünsch A (2009). SSR Markers for fingerprinting Prunus species. Acta Hortic. 814: 689-694.

Wünsch A and Hormaza JI (2002). Molecular characterisation of sweet cherry (Prunus avium L.) genotypes using peach [Prunus persica (L.) Batsch] SSR sequences. Heredity 89: 56-63.

Wünsch A and Hormaza JI (2004). Molecular evaluation of genetic diversity and S-allele composition of local Spanish sweet cherry (Prunus avium L.) cultivars. Genet. Res. Crop Evol. 51: 635-641.

Wünsch A, Gella R and Hormaza JI (2004). Molecular characterization of rootstocks for sweet cherry (Prunus avium L.). Acta Hortic. 658: 599-602.

Xuan H, Wang R, Buchele M, Moller O, et al. (2009). Microsatellite markers (SSR) as a tool to assist in identification of sweet (Prunus avium) and sour cherry (Prunus cerasus). Acta Hortic. 839: 507-514.4 